\title{
Iminência da morte e busca pelo sentido da vida em $A$ morte de Ivan Ilitch ${ }^{\mathrm{I}}$
}

Max Luiz Gimenes

\section{Resumo:}

Texto analítico da novela A morte de Ivan Ilitch (I886), de Lev Tolstói (I828-I9IO), o presente ensaio propõe-se à investigação das relações entre a forma social concreta em que viveu o escritor russo, vista como "ponto de partida" de sua criação artística, e a forma literária construída por ele, o "ponto de chegada" de seu processo criativo, de acordo com a noção de "redução estrutural" proposta por Antonio Candido. Colocando em movimento e diálogo diferentes autores e perspectivas da teoria sociológica, sustenta-se como princípio mediador da passagem de um a outro "ponto", e, portanto, como elemento de estruturação da narrativa, a tensão entre individualidade e vínculo social no contexto de surgimento da sociedade moderna.

Palavras-chave: Literatura e Sociedade - Crítica Literária - Sociologia da Literatura - A morte de Ivan Ilitch - Individualidade e Vínculo Social.

I Versão um pouco modificada do trabalho de conclusão de curso apresentado no primeiro semestre de 2012 à disciplina "Indivíduo, Razão e Liberdade", ministrada na FFLCH-USP, pela profa. Maria Helena Oliva Augusto, a quem sou bastante grato tanto pela oportunidade como pela leitura atenta e comentários pertinentes. 


\section{Considerações preliminares}

A escolha da novela A morte de Ivan Ilitch, de Lev Tolstói, como objeto de estudos deve-se ao reconhecimento de que a obra literária proporciona um material interessante e proveitoso para a análise sociológica e também para a ilustração de conceitos e teorias do campo.

Se lançarmos mão do conceito de "redução estrutural" de Antonio Candido - que este postula como processo por meio do qual determinado autor filtra (por um princípio estrutural ou mediador) o mundo real ("ponto de partida") para reconstituí-lo ficcionalmente no interior de uma estrutura textual como mundo paralelo ("ponto de chegada"), com coerência interna própria, porém com seu texto formado a partir do contexto, mantendo assim uma espécie de "independência dependente" -, torna-se claro que, nesses casos, a constituição bem-sucedida de uma fatura não está, de modo algum, desvinculada da "função exercida pela realidade social historicamente localizada" (GANDIDO 20I0 [I970], p. 28), como admito aqui ser o caso da novela de Tolstói. ${ }^{2}$

Ademais, sendo a crítica "tão inevitável quanto a respiração", compreendendo crítica literária como a articulação do "que passa em nossas mentes quando lemos um livro e sentimos uma emoção sobre ele" (ELIOT I932, p. 3; tradução minha), trata-se então aqui de proceder a tal articulação, racionalização e sistematização com instrumentos próprios da sociologia, para que se tenha como resultado uma contribuição intelectual relevante para a área. A esse propósito este ensaio é dedicado.

\section{Ivan Ilitch no mundo burguês: a individualidade frente ao fenômeno da reificação}

A vida de Ivan Ilitch, juiz do Foro Griminal, é apresentada, no começo do segundo capítulo da novela de Tolstói, como "das mais simples e comuns e, ao mesmo tempo, das mais terríveis" (TOLSTÓI 2006 [I886], p. I7), e não

\footnotetext{
2 Indicações semelhantes a respeito do conhecimento da realidade proporcionado pela literatura podem ser encontradas nos estudos estéticos de outros autores. Para Lukács, por exemplo, "a necessidade da arte se ligava à sua função, ao seu poder de nos proporcionar um conhecimento sensível insubstituível de nossa realidade" (KONDER I996, p. 29). Adorno, por sua vez, sustenta que obras com valor estético constituiriam uma "configuração da verdade", fazendo inclusive menção textual a Tolstói quando dessa passagem (ADORNO; HORKHEIMER I985 [ig44], p. I5).
} 
é exagero enxergar aí a sugestão de que sua vida até ali fora das mais "terríveis" justamente por ter sido das mais "simples" e "comuns".

É interessante notar de antemão como a economia da obra concorre no sentido de comprovar tal constatação: todo o período da vida de Ivan Ilitch que antecede a doença que depois o levará à morte - ao todo quarenta e cinco anos - é narrado em apenas dois capítulos, o segundo e o terceiro; o primeiro capítulo é dedicado à ocasião de seu velório, quando nos é apresentado tanto o próprio protagonista como seu círculo social; e os demais - do quarto ao décimo segundo capítulo - acompanham os cerca de quatro meses da doença de Ivan Ilitch, passando pelas várias nuanças desse breve porém denso período. ${ }^{3}$

Ivan Ilitch viveu no período que Hobsbawm designou como "a era do capital" em livro homônimo, mais ou menos também o mesmo tempo histórico que precedeu a publicação da novela, o qual seguramente serviu, para Tolstói, como "ponto de partida" para a elaboração de suas obras. A seguir farei alguns breves apontamentos histórico-sociais úteis para a compreensão de tal período e, consequentemente, da narrativa que se busca aqui analisar. ${ }^{4}$

Tal período caracterizou-se pela hegemonia do modo de viver burguês, ainda que a burguesia até então não detivesse, na maioria dos países, o poder político, e sua supremacia se desse no âmbito cultural e moral (HOBSBAWM I996 [I977], p. 345). A ideologia liberal da burguesia ascendente marcava uma diferença clara com relação ao modo de vida que a precedeu. Com o modo de produção capitalista, instauravam-se relações sociais não mais estanques, porque a competição individualista trazia mobilidade social, substituindo as relações antes calcadas em questões que transcendiam a vontade do indivíduo pela noção do mérito, apresentado ou aparentado pela conduta de cada um.

Consolidada nesse período histórico, é na forma de sociedade produtora de mercadorias - devido à sua necessária divisão do trabalho, uma vez que o essencial é a produção de valores de uso para os outros (MARX I983 [I867], pp. 43-49) - que ocorre o fenômeno da alienação do trabalho, tão caro para a compreensão do surgimento do fetichismo da mercadoria de que tratou Marx,

3 Credito as observações do parágrafo ao prof. Joaquim Alves de Aguiar, pelos caminhos de interpretação da novela sugeridos em aulas ministradas no segundo semestre de 20II, no Departamento de Teoria Literária e Literatura Comparada da FFLCH-USP. O eventual mau uso de suas ideias, porém, é de responsabilidade apenas do autor do trabalho.

4 Tais apontamentos referem-se principalmente à Europa ocidental e aos Estados Unidos, como regiões de vanguarda desse processo de desenvolvimento do capitalismo e de sua correspondente ordem burguesa, mas de modo algum, ao que parece, são incompatíveis com a compreensão do que começava a ocorrer na Rússia czarista, a despeito de suas reconhecidas especificidades. 
Iminência da morte e busca pelo sentido da vida em A morte de Ivan Ilitch

o qual Lukács trouxe para o centro da crítica marxista. Como anotou Marx, "numa sociedade na qual a forma mercadoria é a forma geral do produto do trabalho, por conseguinte também a relação das pessoas umas com as outras enquanto possuidoras de mercadorias é a relação social dominante". 5

A divisão do trabalho característica dessa ordem social rompe com a unidade do objeto fruto do processo de trabalho e, com a crescente especialização, faz perder de vista a imagem da totalidade (LUKÁCS 20I2 [I922], p. 228). Essa fragmentação do objeto implica necessariamente a fragmentação do sujeito produtor, cuja atividade perde cada vez mais seu caráter "ativo" (id. ibid., p. 203) para tornar-se uma atitude "contemplativa" (id. ibid., p. 204). Esse modo de "objetivação de sua força de trabalho em relação ao conjunto de sua personalidade" é transformado em "realidade cotidiana durável e intransponível", de modo que "a personalidade torna-se o espectador impotente de tudo o que ocorre com sua própria existência" (id. ibid., p. 205).

É claro que, na década de I880, tal processo de desenvolvimento, tanto mais na Rússia czarista, encontrava-se ainda muito incipiente, mas já se fazia sentir, como será sustentado no presente trabalho, a escalada do fenômeno da reificação sobre a individualidade, esvaziando-a paulatinamente de seu caráter ativo e livre, de que é vítima, entre outras personagens, Ivan Ilitch. O que ocorre é que, "desde o dia do seu nascimento, o indivíduo é levado a sentir que só existe um meio de progredir neste mundo: desistir de sua esperança de autorrealização suprema" (HORKHEIMER 2002 [I946], p. I45), o que se torna possível - como realização de algo que não se encontra em si mas fora de si - por meio da "imitação". ${ }^{6}$

5 Admito aqui como fetichismo da mercadoria o fenômeno no qual "os produtos do cérebro humano parecem dotados de vida própria, figuras autônomas, que mantêm relações entre si e com os homens", relações estas que assumem para esses mesmos homens a "forma fantasmagórica de uma relação entre coisas" (MARX I983, p. 7I). Ao serem rebaixados à condição das coisas com as quais interagem nessas relações, os indivíduos nelas inseridos ficam submetidos a um processo de reificação, fenômeno ao qual se dedicou em especial Lukács, com consequências notáveis para o pensamento social contemporâneo, especialmente os de matiz marxista.

6 "Ele [o indivíduo] reage continuamente ao que percebe sobre si, não só conscientemente mas com o seu ser inteiro, imitando os traços e atitudes de todas as coletividades que o rodeiam - seu grupo de jogos, seus colegas de turma, seu time esportivo, e todos os outros grupos que, como já foi indicado, forçam um conformismo mais estrito, uma entrega mais radical à completa assimilação [...]. Através da repetição e da imitação das circunstâncias que o rodeiam, da adaptação a todos os grupos poderosos a que eventualmente pertença, da transformação de si mesmo de um ser humano em membro das organizações, ele consegue sobreviver. A sua sobrevivência se cumpre pelo mais antigo dos meios biológicos de sobrevivência, isto é, o mimetismo" (HORKHEIMER 2002, p. I46). Tal trecho é importante para compreendermos o impacto das condições existentes sobre o indivíduo "médio" da sociedade, tal como Ivan Ilitch é caracterizado textualmente em determinada passagem da narrativa, e também o uso que faremos aqui da sociologia de Goffman, como teoria tradicional (em contraposição à teoria crítica) que se circunscreve nessas condições existentes. 
Voltando a pensar na economia da obra objeto de análise, a esta altura já dispomos de elementos suficientes para buscar responder a esta importante questão: o que pode significar a opção do narrador por dedicar uma atenção tão pequena aos quarenta e cinco anos de toda a vida de Ivan Ilitch, ao passo que dedica parcela muito mais expressiva ao período final dela, o qual corresponde a cerca de quatro meses apenas?

A chave para a resposta encontra-se nas condições históricas e sociais acima apresentadas. Ivan Ilitch, antes do momento em que se percebe doente, vive uma vida média que não passa de uma sobrevivência por mimetismo, por imitação daquilo que as camadas socialmente superiores ofereciam como modelo de conduta, na esperança de que, desse modo e nunca de outro, será bem-sucedido. A sua liberdade para autorrealização da individualidade encontra-se aqui, embora não cerceada formalmente, tolhida na prática pela influência social de seu período histórico, com a tendência ao esvaziamento de sua individualidade de qualquer singularidade relevante a ponto de ter narrados os episódios vividos por ela.

Ivan Ilitch orgulha-se de ter sido um "funcionário extremamente controlado" (TOLSTÓI 2006, p. 20), alguém a agir burocraticamente, independentemente das especificidades das matérias tratadas, controlando rigidamente a divisão entre "obrigações funcionais" e "vida particular" (id. ibid., p. 2I) e encarando como estorvo à atividade funcional "toda aquela parte úmida da vida cotidiana" (id. ibid., p. 33), aquela parte humana untada pela emoção e recheada de viva capacidade de criação. A tensão entre o tempo de trabalho e o tempo livre passado com a família vem à tona, e a solução, para Ivan Ilitch, é tornar seu tempo livre com a família uma extensão do tempo de trabalho, arrastando para essa outra parte de sua vida a mesma impessoalidade e secura com que levava as atividades funcionais. ${ }^{7}$

O casamento de Ivan Ilitch ocorrera menos por amor e identificação de ideal comum de vida do que por cálculo, embora o casal nutrisse à época notável simpatia e entusiasmo um em relação à imagem do outro, principalmente ela, Prascóvia Fiódorovna, que chegara até a apaixonar-se por ele. É evidente que problemas conjugais se sucederiam no convívio, trazendo um enorme

7 Não será o caso de desenvolver extensamente neste trabalho, mas o jogo de cartas a que Ivan Ilitch se entrega como ponto alto de sua diversão (que consiste simplesmente em matar o tempo com uma atividade esvaziada de força criativa) poderia ser situado no que Adorno (2002 [Ig69]) considerou como forma de adestramento do comportamento do indivíduo para o trabalho, com toda a busca competitiva pelo sucesso e a relação fetichizada com a ideia de "destino", peculiar a esse tipo de distração. 
Iminência da morte e busca pelo sentido da vida em A morte de Ivan Ilitch

tédio para a vida familiar, do qual Ivan Ilitch fugiria se entregando ainda mais a seu trabalho. ${ }^{8}$

Passando cada vez menos tempo com a família, Ivan Ilitch acaba por esgotar igualmente as possibilidades de distração em seu trabalho, envolvendo-se em problemas também nele, relativos a promoções etc. Resolve então tirar uma licença e ir com a família à casa de campo de parentes da esposa, opção feita a fim de economizar, afinal estavam vivendo a essa altura acima dos próprios meios. Lá, sem as obrigações do serviço, Ivan Ilitch é tomado por um tédio ainda maior, nunca antes vivenciado, uma "angústia intolerável" (id. ibid., p. 28). Com a volta para casa, após alguns contatos e certo golpe de sorte, ele resolve seus problemas profissionais e financeiros com a designação para uma função diferente, a qual o colocou acima de seus colegas de trabalho e com o ordenado desejado, além de tê-lo deixado "completamente feliz" (id. ibid., p. 29).

Nota-se, porém, que a angústia ocasionada pela ausência das atividades funcionais pelo breve período de licença escancarara o modo alienado de seu trabalho e o caráter reificado de sua individualidade, a ponto de ele ter se mostrado disposto, antes de atingir a nova designação, a exercer urgentemente qualquer tipo de atividade melhor remunerada: "Agora, não fazia já questão de um ministério determinado, uma direção ou setor de atividade. Precisava simplesmente de um emprego, um emprego com ordenado de cinco mil" (id. ibid., p. 28). O importante era que o pagamento fosse aquele que permitisse a ele o padrão de consumo desejado, sendo este uma das únicas formas de conseguir harmonia conjugal, ou seja, com a distração de ambos com a aquisição incessante de mercadorias. ${ }^{9}$

O tédio, no entanto, não desaparece, é apenas escamoteado, permanecendo à espreita, apto a voltar à tona tão logo os indivíduos sejam novamente entregues ao desespero de uma autonomia incapaz de fazer de si algo produtivo para si próprio. ${ }^{\text {IO }}$

8 Neste ponto, é importante notar que, diferentemente do que ocorre na fase atual do capitalismo, o fenômeno da reificação encontrava-se muito menos desenvolvido, e consequentemente o tédio no exercício funcional, ainda mais para um magistrado, não pode ser equiparado mecanicamente ao de hoje. 9 Em passagem que parece feita sob medida para aplicação à narrativa, Hobsbawm assinala: "O lar era a quintessência do mundo burguês, pois nele, e apenas nele, podiam os problemas e contradições daquela sociedade ser esquecidos ou artificialmente eliminados. Ali, e somente ali, os burgueses e mais ainda a família pequeno-burguesa podiam manter a ilusão de uma alegria harmoniosa e hierárquica, cercada pelos objetos materiais que a demonstravam e faziam-na possível [...]” (HOBSBAWM I996, pp. 32I-22). Io A vida tediosa de Ivan Ilitch é escancarada de forma mordaz pela narrativa, que mostra que no jogo de cartas, para se distrair do tédio, Ivan Ilitch gostava de ganhar modestamente, pois de modo diverso 


\section{A moral do mundo burguês e a apresentação do eu reificado na vida cotidiana}

Admitirei, neste segundo momento da abordagem, a despeito de suas eventuais insuficiências, as teorias de Durkheim, no que diz respeito à moral, e as de Goffman, no que tange ao manejo dos equipamentos expressivos para o desempenho de papéis sociais em interações com uma determinada plateia. Considerarei, como fez Adorno em relação à teoria do tédio de Schopenhauer já mencionada anteriormente em nota, que as contribuições desses autores ao menos descrevem muito bem o que ocorre com as pessoas sob as condições sociais atuais, ou seja, de submissão do indivíduo ao fetichismo da mercadoria. ${ }^{\text {II }}$

Entendendo que há para todos os indivíduos que compõem uma coletividade uma moral comum (DURKHEIM I970 [I906], p. 47), esta entendida como regra de conduta (id. ibid., p. 42), a tarefa que nos cabe é buscar encontrar que moral era essa a que Ivan Ilitch e seu entorno social estavam submetidos e como tal submissão se manifestava. Antes, porém, faz-se necessário distinguir aqui os dois aspectos que assume a realidade moral: aspecto objetivo e subjetivo.

O aspecto objetivo, do qual se ocupa Durkheim, é esse que "serve como ponto de referência comum e impessoal para julgar as ações" (id. ibid., p. 48). Ponto de referência também, portanto, para a escolha, por parte dos indivíduos, de papéis e modos de desempenhá-los frente à sociedade, bem como ponto de referência para a atribuição a eles de estigma ou prestígio, por meio da imputação de seus respectivos símbolos. Já o aspecto subjetivo estaria ligado à diversidade de percepções dessa moral comum pelas consciências individuais. ${ }^{12}$

não ficava bem-humorado, ao contrário, sentia uma "sensação desagradável" (TOLSTÓI 2006, p. 35). Considerando uma referência de Adorno à teoria sobre o tédio de Schopenhauer, fica evidente a aplicação dela a esse episódio: "ou as pessoas sofrem pelo apetite insatisfeito de sua cega vontade, ou se entediam tão pronto aquele esteja satisfeito" (ADORNO 2002, p. IOg). O ideal seria, portanto, aquele ponto nebuloso de tensão entre a não satisfação e a satisfação, o "ganho modesto".

II Note-se que, com relação a Goffman, a referência de Adorno não parece passar de um vago reconhecimento de sua existência e de seu entendimento de que os indivíduos, no desempenho de um papel social, não dispõem de si mesmos com real liberdade, e isto considerando que ele o incluía no que chamou de "aquelas sociologias conciliadoras que utilizam o conceito de papéis como chave" (ADORNO 2002, p. IO3). Quanto a Durkheim, até pelo distanciamento temporal, a atenção de Adorno parece diferenciada, e não nos ocuparemos aqui desse levantamento.

I2 O paralelo entre o aspecto subjetivo da moral em Durkheim - não passível de total socialização - e a reserva do indivíduo quanto ao que lhe é imposto pela indústria cultural em Adorno e Horkheimer - o que demonstra a não atrofia total da capacidade imaginativa individual - é sugerido implicitamente e de 
Iminência da morte e busca pelo sentido da vida em A morte de Ivan Ilitch

Numa sociedade cuja orientação é para a produção de mercadorias, a moral vigente, em consonância com a realidade das relações sociais de produção, apresenta-se ao indivíduo como algo alheio, natural e imutável. Tal era a moral burguesa hegemônica já nesse fim de domínio político aristocrático. Sendo a moral esse conjunto de regras de conduta, as quais os indivíduos cumprem por dever e por considerarem tal cumprimento um bem, ${ }^{13}$ Ivan Ilitch buscará também cumpri-la, mesmo não sabendo em que de fato ela consiste, mas apenas caracterizando a conduta moral como a vida levada de maneira "leve, agradável, alegre e sempre decente e aprovada pela sociedade" (TOLSTÓI 2006, pp. 23-24) e os atos morais como atos "comme il faut" (como é preciso), expressão francesa que será recorrente para mostrar a submissão a essa ordem externa que não se entende bem mas que se cumpre, o que é acentuado pela forma afrancesada em meio ao falar russo.

Desse modo, surge como característica desse tempo a hipocrisia (HOBSBAWM I996, pp. 324-25), como ação que escancara o interior ("espiritual") em contradição com o exterior ("material"), e a tendência de adequar aquele a este aparece como resposta à dualidade espiritual/material da sociedade burguesa. O primeiro capítulo da novela, desde a notícia da morte até o velório de Ivan Ilitch, esbanja momentos em que há uma escandalosa discrepância entre os sentimentos provocados nos indivíduos regidos pelo modo de viver burguês e a necessidade de manterem "certas obrigações", ${ }^{14}$ sob risco de sanções, consequência esta não ligada ao ato em desacordo com as obrigações morais em si, mas por um laço sintético atribuído pela moral.

passagem por Cohn (I998, p. 24) e levado em conta no presente trabalho, embora o último elemento do paralelo se refira a um fenômeno característico de estágio de desenvolvimento do capitalismo posterior à obra aqui analisada.

I3 Cabe aqui, perfeitamente, a lembrança de Horkheimer de que "a economia burguesa estruturou- se de tal forma que os indivíduos, ao perseguirem a sua própria felicidade, mantenham a vida da sociedade" (HORKHEIMER I989 [I937], p. 48), iludidos por um eudemonismo que os impele à obediência de uma moral que lhes é estranha e que jamais lhes permitiria a autorrealização, quando muito a realização de um plano que não lhes dissesse diretamente respeito.

I4 Hobsbawm assinala que a hipocrisia consciente é mais facilmente encontrada nesse tipo de sociedade, em que "a diferença entre a moralidade oficial e as demandas da natureza humana seja intransponível” (HOBSBAWM I996, p. 324). Tal hipocrisia não deveria ser entendida como trapaça, mas possivelmente como sobrevivência nas condições existentes. É assim com a esposa de Ivan Ilitch, que diz na nota de falecimento de seu marido no jornal que ele era seu "amado esposo" (TOLSTÓI 2006, p. 7), mesmo tendo chegado a odiá-lo e a ansiar por seu fim às vésperas de sua morte; é assim, também, com os colegas de trabalho do protagonista, que ao mesmo tempo em que lamentam o ocorrido deixam de fazê-lo no instante seguinte em meio a especulações a respeito das movimentações profissionais vantajosas que a abertura de uma vaga poderia proporcionar. 
Uma passagem interessante, que é exemplar desse laço sintético entre o ato de apresentar a si numa determinada situação e as consequências que eventualmente poderiam decorrer de um manejo equivocado dos equipamentos expressivos e de uma impressão inadequada causada nos outros, é a do desempenho de Piotr Ivânovitch, colega de trabalho de Ivan Ilitch, no velório deste último:

Piotr Ivânovitch entrara naquela casa sem saber, como sempre acontece, o que deveria fazer ali. Sabia uma coisa: que nesses casos nunca é demais fazer o sinal da cruz. Não tinha muita certeza se era necessário também inclinar-se, e, por isso, escolheu uma solução intermediária: entrando no quarto, começou a persignar-se e como que a inclinar-se um pouco (TOLSTÓI 2006, p. IO).

Não é a única passagem. Ao final de sua permanência no quarto, quando a imagem do morto começa a perturbar-lhe o pensamento, ele tem

uma sensação desagradável, por isto persignou-se mais uma vez rapidamente, em seguida virou-se e caminhou para a porta, segundo lhe pareceu com demasiada rapidez, que contrariava as regras da decência (id. ibid., p. II).

E que "regras da decência" seriam essas com base nas quais agem os indivíduos para causar a impressão desejada nos outros com quem interagem?

Como já foi dito, no decorrer da narrativa Ivan Ilitch faz referência ao modo de viver "decente", e esse modo de viver adequado em nenhum momento é definido em termos de conteúdo, apenas em relação à conduta aprovada pela sociedade. É, portanto, algo alheio ao indivíduo, ao qual este é obrigado a se submeter, com a apresentação de um "eu" que não é ele mesmo, mas outro que a sociedade gostaria de ver nele (um apêndice dela que lhe seja funcional?) e que, de certa forma, acaba se confundindo com a própria existência do indivíduo no afã deste por sua sobrevivência, mimética, não estando essa individualidade sujeita, no entanto, a total socialização, como mencionado anteriormente em nota a propósito do paralelo entre moral subjetiva e reserva dos indivíduos na recepção dessa moral.

Tanto é indissociável da hipocrisia tal moral, que Ivan Ilitch, quando ao longo de sua vida chegou a cometer atos que considerava de antemão contrários à vida decente, mudou de opinião tão logo encontrou no comportamento das altas camadas da sociedade aprovação para determinados tipos de comportamento duplo, como parece ter sido o caso de sua entrega a paixões e vícios quando jovem. Tal influência das camadas superiores como referên- 
Iminência da morte e busca pelo sentido da vida em A morte de Ivan Ilitch

cia é bastante perceptível, e poderíamos citar como exemplo o episódio que justifica o exagero no uso de expressões de língua francesa por parte de Ivan Ilitch e sua esposa, bem como do narrador como ironia: esse uso advém da imitação de um chefe que Ivan Ilitch tivera, o qual, juntamente com a esposa, considerava-o um "bon enfant" (bom menino). Tal emprego de expressões seria o que Goffman (I980 [I963]), em contraposição aos símbolos de estigma, considerou serem os "símbolos de prestígio". ${ }^{\text {I5 }}$

A imitação parece mesmo ser a regra nessas condições, fazendo com que a sociologia dos papéis de Goffman, embora não explique a gênese ou o funcionamento dessas mesmas condições do ponto de vista da totalidade que compõem, seja uma descrição bastante precisa do modo como opera o mecanismo de sobrevivência do indivíduo que interage sob tais condições sociais, que o impelem ao mimetismo.

Ivan Ilitch e sua família, que empregavam criados, ${ }^{16}$ podem ser considerados como parte da camada média daquela sociedade, os quais haviam ascendido e se tornado a própria imagem do arrivista. E "como, de que outra forma, poderiam os bem-sucedidos burgueses demonstrar o seu sucesso, tendo ou não poder político enquanto classe? A palavra parvenu (novo rico) automaticamente se tornou sinônimo de gastador destemperado" (HOBSBAWM i996, p. 329).

Vejamos a semelhança entre as passagens da novela e a análise do historiador:

Comecemos nossa análise dessa sociedade, que atingiu seu apogeu no período que tratamos, pela aparência das roupas que seus membros usavam, pelos interiores que os cercavam. "O traje faz o homem", dizia um ditado alemão, e nenhuma época seguiu mais à risca tal ideia do que a época em que a mobilidade social poderia de fato colocar numerosas pessoas dentro da situação histórica inteiramente nova de desempenhar papéis sociais novos (e superiores), tendo que usar as roupas apropriadas (id. ibid., p. 32I, grifos meus).

I5 Símbolos de status ou de prestígio servem para informar socialmente "uma pretensão especial a prestígio, honra ou posição de classe desejável” (GOFFMAN I980, p. 53). Como símbolo de estigma, do qual Ivan Ilitch e sua esposa procuram se afastar, podem ser citados os amigos e a parentela menos favorecida socialmente, "uns pés-rapados" (TOLSTÓI 2006, p. 35), os quais eles enxotavam pois, "em certas circunstâncias, a identidade social daqueles com quem o indivíduo está acompanhado pode ser usada como fonte de informação sobre a sua própria identidade social, supondo-se que ele é o que os outros são" (GOFFMAN I980, pp. 57-58).

I6 A presença de criados é considerada por Hobsbawm marca de distinção em relação aos que não os possuíam, "socialmente inferiores" (HOBSBAWM i996, p. 332). 
Que outro modo de imitação da burguesia excessivamente gastadora seria melhor senão o de gastar também, dentro das próprias limitações, para ostentar tal gasto?

$\mathrm{Na}$ realidade, havia ali [no apartamento de Ivan Ilitch] o mesmo que há em casa de todas as pessoas não muito ricas, mas que desejam parecê-lo e por isto apenas se parecem entre si: damascos, pau-preto, flores, tapetes e bronzes, matizes escuros e brilhantes; enfim, aquilo que todas as pessoas de determinado tipo fazem para parecer com todas de determinado tipo (TOLSTÓI 2006, p. 3I).

Vemos com esse paralelo a importância da imitação na vida dos indivíduos inseridos nessa ordem social nova, na qual grande importância passa a ser dada nas interações entre eles para a definição de seus papéis, ao que Goffman (2008 [I959]) classificou como "fachada", com referência à fachada pessoal ("aparência") e ao cenário ("interiores que os cercavam"). ${ }^{17}$

\section{A iminência da morte como momento privilegiado para oposição da individualidade ao fenômeno da reificação}

Pelo que vimos até aqui, não é de espantar que, em tal mundo burguês, a ideia da morte seja "cada vez mais afastada do universo dos vivos" (BENJAMIN I994 [I936], p. 207), como se tal destino, o único certo a todos os homens, não lhes dissesse respeito, fosse algo que se aplica ao homem abstrato, jamais a si próprio. Quando Ivan Ilitch morre ${ }^{18}$ não são poucos os que, a seu redor,

I7 A parte da fachada pessoal que para Goffman corresponde à "maneira" - "estímulos que funcionam no momento para nos informar sobre o papel de interação que o ator espera desempenhar na situação que se aproxima" (GOFFMAN 2008, p. 3I) - pode ser percebida ao longo da narrativa, por exemplo, na relação de Ivan Ilitch no uso de sua autoridade em relação às pessoas sujeitas ao seu julgamento no tribunal bem como na relação dele com os médicos que o examinam, os quais, por meio de "palavras imprecisas" e "termos científicos confusos", transpareciam um "ar importante e artificial, doutoral" (TOLSTÓI 2006, pp. 37-39), buscando assegurar na interação seu lugar de autoridade, sua legitimidade, acima de quaisquer questionamentos.

I8 Ivan Ilitch, após um acidente causado pela decoração do interior de seu apartamento, passou a sentir dores laterais crescentes, que culminariam no sofrimento excessivo dos últimos dias e no instante tranquilo de seu passamento. Essa dor, que alguns dos médicos atribuíram ao rim, embora nada tenha sido comprovado em relação à causa da doença mesmo depois da morte do protagonista, era também na região do baço, o qual parece fazer fronteira com o rim esquerdo e que, em língua inglesa ("spleen"), 
Iminência da morte e busca pelo sentido da vida em A morte de Ivan Ilitch

chegam a alegrar-se depois do impacto da triste notícia, com o pensamento irrefletido de que morrera outro e não eles próprios.

No decorrer dos últimos séculos, pode-se observar que a ideia da morte vem perdendo, na consciência coletiva, sua onipresença e sua força de evocação. [...] Durante o século XIX, a sociedade burguesa produziu, com as instituições higiênicas e sociais, privadas e públicas, um efeito colateral que inconscientemente talvez tivesse sido seu objetivo principal: permitir aos homens evitarem o espetáculo da morte (id. ibid., p. 207)

Que riscos à coesão dessa ordem burguesa, à sua moral, poderia significar a presença da ideia da morte?

Ora, é no momento da morte que o saber e a sabedoria do homem e sobretudo sua existência vivida - e é dessa substância que são feitas as histórias - assumem pela primeira vez uma forma transmissível. Assim como no interior do agonizante desfilam inúmeras imagens - visões de si mesmo, nas quais ele se havia encontrado sem se dar conta disso -, assim o inesquecível aflora de repente em seus gestos e olhares, conferindo a tudo o que lhe diz respeito aquela autoridade que mesmo um pobre-diabo possui ao morrer, para os vivos ao seu redor (id. ibid., p. 207).

Percebemos agora que não foi à toa a saída "com demasiada rapidez" de Piotr Ivânovitch do quarto em que se encontrava Ivan Ilitch morto, rapidez esta que "contrariava as regras da decência", conforme menção anterior. Piotr Ivânovitch se deparara justamente com a "lembrança aos vivos" que havia na expressão de Ivan Ilitch estirado em seu caixão, o qual, "como todos os defuntos, tinha o rosto mais belo e, sobretudo, mais significativo do que fora em vida" (TOLSTÓI 2006, p. II). O amigo, incomodado, tratou de sair dali correndo a fim de distrair-se com um bom carteado.

E que lembrança aos vivos seria essa que um indivíduo como Ivan Ilitch teria para compartilhar?

E ele começou a examinar na imaginação os melhores momentos da sua vida agradável. Mas, fato estranho, todos estes momentos melhores de uma vida agra-

tem o mesmo significado de "tédio"; limito-me aqui ao registro dessa aparente sugestão do narrador de que, no fundo, a verdadeira causa da morte de Ivan Ilitch estaria ligada ao tédio. 
dável pareciam agora completamente diversos do que pareceram então. Tudo, exceto as primeiras recordações da infância. [...]

E apenas começava aquilo que resultara no seu eu atual, Ivan Ilitch, tudo o que parecia então ser alegria derretia-se aos seus olhos, transformando-se em algo desprezível e frequentemente asqueroso.

E quanto mais longe da infância, quanto mais perto do presente, tanto mais insignificantes e duvidosas eram as alegrias (id. ibid., pp. 66-67).

Como perceberam alguns autores, entre os quais Benjamin, o sentido de uma vida "somente se revela a partir de sua morte" (BENJAMIN I994, p. 2I4). O que está em risco, então, é o aperceber-se de que a pessoa à beira da morte "não tinha de fato vivido" (id. ibid., p. 212), ou seja, a tomada de consciência, por meio da porta da moral subjetiva do indivíduo, a reserva frente à moral objetiva, de que a vida reificada daquela pessoa fora sem sentido:

Veio-lhe à mente [de Ivan Ilitch]: podia ser verdade aquilo que lhe parecera antes uma impossibilidade total, isto é, que tivesse vivido a sua existência de maneira diversa da devida. Veio-lhe à mente que as suas veleidades quase imperceptíveis de luta contra aquilo que as pessoas mais altamente colocadas consideravam correto, veleidades quase imperceptíveis que ele imediatamente repelia, podiam ser justamente as verdadeiras, e tudo o mais ser outra coisa. O seu trabalho, o arranjo da sua vida, a sua família, e esses interesses da sociedade e do serviço, tudo isto podia ser outra coisa. Tentou defender tudo isto perante si. E de repente sentiu toda a fraqueza daquilo que defendia. E não havia o que defender.

[...] Via neles [esposa, filha, médico] a si mesmo, tudo aquilo de que vivera, e via claramente que tudo aquilo era não o que devia ser, mas um embuste horrível, descomunal, que ocultava tanto a vida como a morte (TOLSTÓI 2006, p. 72).

E tal é então a funcionalidade do afastamento da ideia da morte no mundo burguês, o de evitar a reflexão dos vivos enquanto há tempo sobre a própria existência e garantir assim a manutenção dessa ordem social, pois do contrário tal sociedade estaria sujeita à desagregação, e os indivíduos isolados pertencentes a ela, a um possível estado de anomia. Basta lembrar, por exemplo, que nesse momento Ivan Ilitch caracteriza como "trabalho morto" (id. ibid., p. 67) sua antes adorada atividade funcional orientada pela busca de dinheiro.

É o que Ivan Ilitch percebe quando de sua doença, que os casos a serem julgados no trabalho não lhe interessavam mais, o que lhe interessava era o "seu caso", o caso do sentido de sua própria existência, que ele precisava avaliar se fora vivida satisfatoriamente, afinal já percebia a sombra 
Iminência da morte e busca pelo sentido da vida em A morte de Ivan Ilitch

da morte a lhe espreitar. Com a consciência da morte, inescapável, cada um passaria a cuidar também de seu caso, de trabalhar para a própria realização, e não mais a realização por meio de si de algo que lhe seja alheio. A iminência da morte impele ao balanço e à descoberta do sentido da própria vida, ou da ausência dele, o momento em que se descobre se ela valeu ou não a pena. O sacrifício a que estamos todos submetidos (vender como mercadoria nossa força de trabalho para adquirir outras mercadorias para a satisfação de nossas necessidades), com postergação crescente da recompensa de prazer que tal esforço promete, demonstra como tal ideia, a da morte, tornaria insustentável a ordem social burguesa.

Há, a partir do sexto capítulo da novela, uma opção de Ivan Ilitch por falar menos e pensar mais, que se consolida do nono em diante. Neste, ocorre a explosão de um choro seguido de profundo exercício de reflexão crítica, e nesse momento o narrador dá voz aos pensamentos do protagonista, cedendo-lhe, por meio do recurso das aspas, a palavra, como uma espécie de reconhecimento de sabedoria e de aproximação, como se o narrador compreendesse aquilo por que ele estava passando. ${ }^{19}$

Ao fim, já admitindo que não vivera como se deve e considerando como emaranhado de mentiras a moral vigente, Ivan Ilitch reconhece a dignidade de apenas duas das personagens ao seu redor: o jovem criado vindo do campo Guerássim, cuja simplicidade e ingenuidade ainda não haviam sido corrompidas pelo modo de vida burguês e sua hipocrisia, e seu filho, Vassíli Ivânovitch, visto como "coitado" e menos importante para os outros e também para o pai no período em que este esteve são, durante o qual quase toda a atenção, no que diz respeito à família, era dedicada à esposa e à filha, as quais ele passou depois a não mais suportar, por ver nelas justamente aquilo que havia sido e o que, nesse momento, gostaria de esquecer.

Como informou a viúva de Ivan Ilitch a Piotr Ivânovitch por ocasião do velório do marido, este esteve consciente de tudo até o último instante. Não sabia ela, pelo distanciamento que se operou entre ambos conforme Ivan Ilitch caía em direção à morte, que ele esteve não apenas consciente, mas talvez consciente como nunca fora antes nesses seus últimos instantes de vida.

I9 Credito também as observações desse parágrafo ao prof. Joaquim Alves de Aguiar e suas aulas sobre a novela. 


\section{Referências bibliográficas}

ADORNO, Theodor. Tempo livre. In: Indústria cultural e sociedade. São Paulo: Paz e Terra, 2002, pp. IO3-I7. ; HORKHEIMER, Max. Dialética do esclarecimento: fragmentos filosóficos. Rio de Janeiro: Zahar, I985.

BENJAMIN, Walter. O narrador: considerações sobre a obra de Nikolai Leskov. In: Obras escolhidas. São Paulo: Brasiliense, I994. v. I, pp. I97-22I.

CANDIDO, Antonio. Dialética da malandragem. In: O discurso e a cidade. Rio de Janeiro: Ouro sobre Azul, 2010, pp. 19-54.

COHN, Gabriel. A atualidade do conceito de indústria cultural. In: MOREIRA, Alberto da Silva. Sociedade global: cultura e religião. Petrópolis: Vozes, I998, pp. II-26.

DURKHEIM, Émile. Determinação do fato moral. In: Sociologia e Filosofia. Rio de Janeiro; São Paulo: Forense, I970, pp. 43-69.

ELIOT, Thomas Stearns. Tradition and the Individual Talent. In: Selected Essays. Nova York: Harcourt, Brace and Company, I932, pp. 3-II.

GOFFMAN, Erving. A representação do eu na vida cotidiana. Petrópolis: Vozes, 2008. . Estigma: notas sobre a manipulação da identidade deteriorada. Rio de Janeiro: Zahar, I980.

HOBSBAWM, Eric. O mundo burguês. In: A era do capital. Rio de Janeiro: Paz e Terra, I996, pp. 32I-47.

HORKHEIMER, Max. Ascensão e declínio do indivíduo. In: Eclipse da razão. São Paulo: Centauro, 2002, pp. 133-65.

. Teoria tradicional e teoria crítica. In: . Textos escolhidos. São Paulo: Nova Cultural, I989, pp. 3I-68.

KONDER, Leandro. Estética e política cultural. In: Lukács: um Galileu no século XX. São Paulo: Boitempo, I996, pp. 27-33.

LUKÁCS, Georg. O fenômeno da reificação. In: História e consciência de classe. São Paulo: WMF Martins Fontes, 2012, pp. 194-239.

MARX, Karl. A mercadoria. In: O capital. São Paulo: Abril Cultural, I983, v. I, pp. 45-78.

TOLSTÓI, Lev. A morte de Ivan Ilitch. São Paulo: Editora 34, 2006.

Max Luiz Gimenes - Graduando em Giências Sociais pela Universidade de São Paulo. max.gimenes@gmail.com 